\title{
ELECTROCARDIOGRAPHIC CHANGES AT HIGH ALTITUDE
}

\author{
BY

\section{J. S. MILLEDGE*} \\ From the Medical Research Council Laboratories, Department of Human Physiology, Holly Hill, London ,
}

Received February 27, 1962

This paper reports the results of serial electrocardiograms taken on climbers, during the 1960-61 Himalayan Scientific and Mountaineering Expedition, who spent approximately five months at $19,000 \mathrm{ft}$. and later shorter periods at higher altitudes. The effect of oxygen breathing and exercise on the cardiogram was also studied.

\section{SubJeCtS AND MethodS}

Fifteen subjects had cardiograms recorded. Of these, four were Sherpas, on whom only single records were taken at the winter station. For reasons of clarity, the quantitative results reported are from six subjects on whom most work was done. Their age and weight are shown in Table I; they all acclimatized well by normal climbing criteria. The cardiograms of the other subjects all showed the same trends.

TABLE I

Age and Weight of the Six Principal Subjects After 7-14 Weeks at 19,000 ft

\begin{tabular}{lll|r|r|r|r|r|r}
\hline & & & M.G. & J.M. & T.N. & W.R. & J.W. & M.W. \\
\hline \begin{tabular}{lll|r|r|r} 
Age (years) \\
Weight (lb.)
\end{tabular} & $\ldots$ &.. & 23 & 30 & 31 & 29 & 32 & 35 \\
\hline
\end{tabular}

Sea-level cardiograms were taken from all subjects before the start of the expedition in London, except for three subjects who came from New Zealand (one, W.R., is included in the six subjects in Table I), and their records were first recorded at $10,000 \mathrm{ft}$. during the march in.

After reaching altitude, cardiograms were recorded throughout the nine-month expedition at approximately monthly intervals. A few records were taken at a transit camp at $17,500 \mathrm{ft}$. early in the expedition. The majority were taken at our winter station, the silver hut, at 19,000 ft., including cardiograms taken during oxygen breathing and after exercise. Finally, seven curves were recorded at Camp III $(21,000 \mathrm{ft}$.) and six at Camp V (24,400 ft.) on Makalu. It was not possible to study in detail the reversion back to normal of the cardiogram on return to sea-level, but one subject, M.W., who was flown out to Kathmandu (4,000 ft.) had a cardiogram taken the day after arrival. Four other subjects had cardiograms taken three to four months after returning home.

The apparatus used was a Cambridge transrite cardiograph which performed admirably. Care had to be taken to keep the batteries warm otherwise the trace became very faint. There was no difficulty in this at the silver hut where the indoor temperature was usually $60-80^{\circ} \mathrm{F}\left(15 \cdot 6-26 \cdot 7^{\circ} \mathrm{C}\right.$.). But difficulty was encountered at the high camps on Makalu.

Another technical difficulty in the highest camp was the appearance of irregular sinusoidal waves in the cardiogram which we thought to be due possibly to the static electricity generated in the fabric of the nylon tent by the high wind in this camp. It disappeared when the wind dropped.

* Present address: Christian Medical College and Hospital, Post Box No. 3, Vellore, Madras State, South India. 
Standard 12-lead cardiograms were taken using V leads across the præcordium. The subjects were lying down. When oxygen was administered it was via a small closed circuit set giving 100 per cent $\mathrm{O}_{2}$ or $\mathrm{PIO}_{2}$ of about $300 \mathrm{~mm}$. $\mathrm{Hg}$ (barometric pressure at $19,000 \mathrm{ft}$., $380 \mathrm{~mm}$. $\mathrm{Hg}$ ). During the first two oxygen experiments cardiograms were taken at five-minute intervals; later a single record was taken after 30 minutes while still on oxygen. On one occasion a subject took "sleeping oxygen" at $0.51 . / \mathrm{min}$. for nine hours overnight and the cardiogram was repeated in the morning.

The effect of exercise on the cardiogram was studied as follows. A routine record was taken at rest. The subject with electrodes still attached then exercised on the stationary bicycle for 25 minutes, working up to a rate of $900 \mathrm{~kg} . \mathrm{m} . \mathrm{min}$., the maximal for the altitude. A second cardiogram was then recorded as soon as possible on stopping exercise, usually within one and a half minutes.

\section{RESULTS}

The principal changes found in the cardiogram at altitude are in the QRS complex and are best described vectorially. In the frontal plane projection of the mean QRS vector (ÂQRS) there is a shift to the right (right axis deviation). There is also a decrease in the amplitude of the QRS voltage. In the sagittal plane there is a backward shift of the vector.

Right Axis Deviation. This change with altitude is shown in Fig. 1 and 2. In Fig. 1 the results from 5 of the 6 subjects on whom there are most data are plotted. The sixth subject developed an S1, S2, S3 pattern (Fig. 3), but by plotting the initial and terminal $0.04 \mathrm{sec}$. of the QRS complex it was possible to show that the two vectors moved in the same direction as the mean QRS vectors of the other subjects.

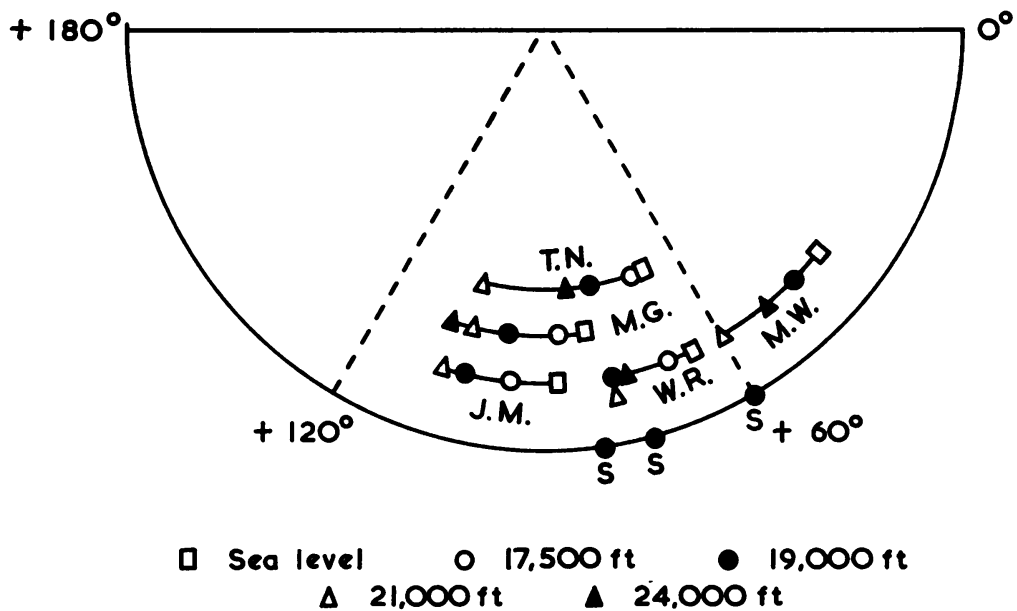

FIG. 1.-Change of frontal projection of mean QRS vector with altitude. Five subjects on whom most data are available, with the position of the single record from three Sherpas (S) at 19,000 ft. also shown. Distance of each subject's line from the centre does not indicate the magnitude of the vector.

It will be seen that although there is considerable variation from subject to subject the trend is for the shift to increase with altitude. There was no obvious change with time spent at a given height. On return to sea-level the ÂQRS had reverted to normal even in the earliest cardiogram taken 24 hours after leaving 15,000 ft.

Amplitude. As Table II shows, there is a decrease in amplitude of the QRS vector on going to high altitude, but this is accompanied by a backward shift in the sagittal plane (see below), which might account for it. 


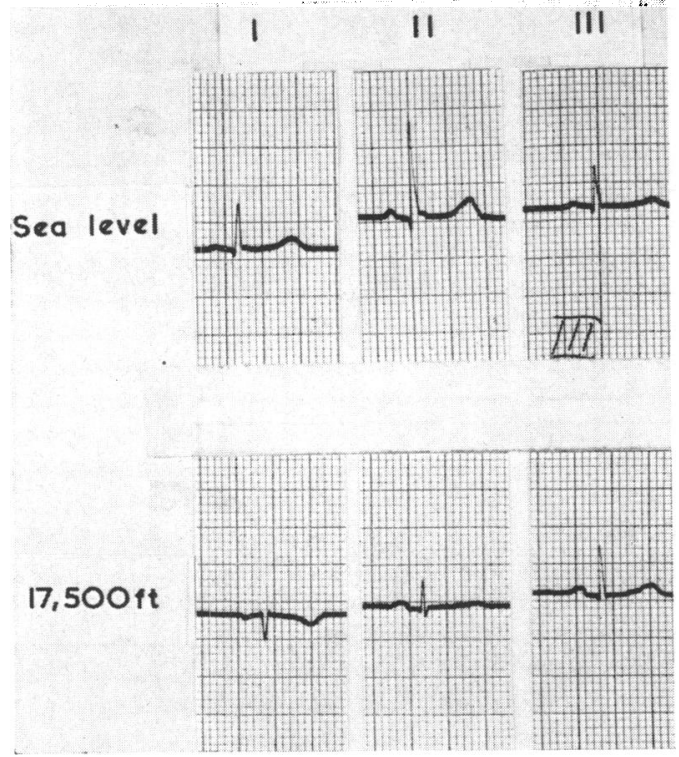

Fig. 2. - Right axis deviation, standard leads. Subject B.C.B. (not shown in Fig. 1). No other subject showed such a marked axis shift, even at greater heights.
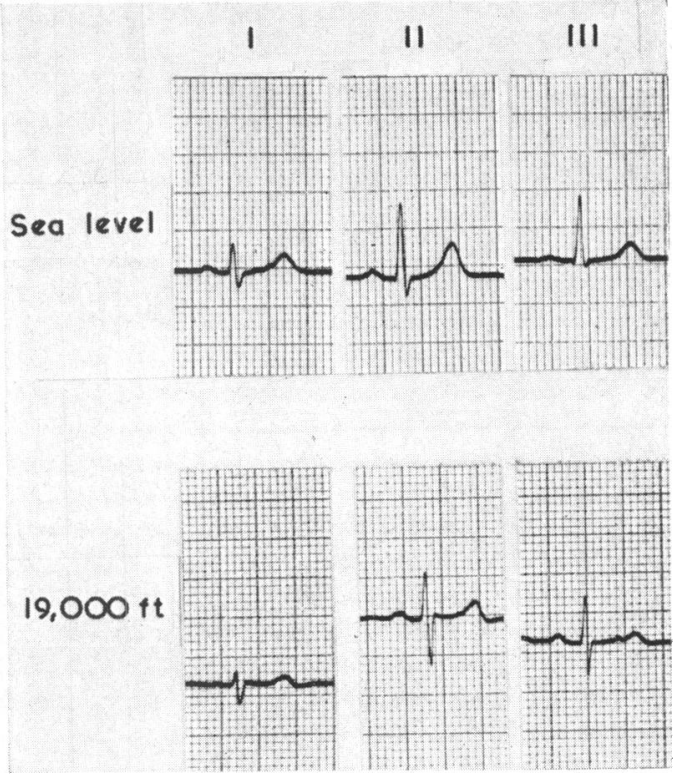

Fig. 3.-Subject J.W. Development of S1,S2,S3 pattern.

Sagittal Plane Projection of QRS. Fig. 4 and Table II show the change in the biphasic wave pattern or transitional zone (T.Z.) across the chest from V2-3 to V5-6, with increase in altitude and length of time spent at altitude. This change, indicating a backward shift of the mean QRS vector, was the most constant finding in all subjects. On return from high altitude, the transitional zone returned to sea-level position in all cardiograms.

$T$ Wave and $S-T$ Segment. Inversion of the $T$ wave was found in all subjects in the right præcordial leads, and tended to spread across the chest during the winter at 19,000 ft. (Fig. 4 and 5).

TABLE II

Amplitude (in V) of Mean QRS Vector, Frontal Plane Projection, and Transitional Zone (T.Z.) of Mean QRS from Negative to Positive in Precordial Leads

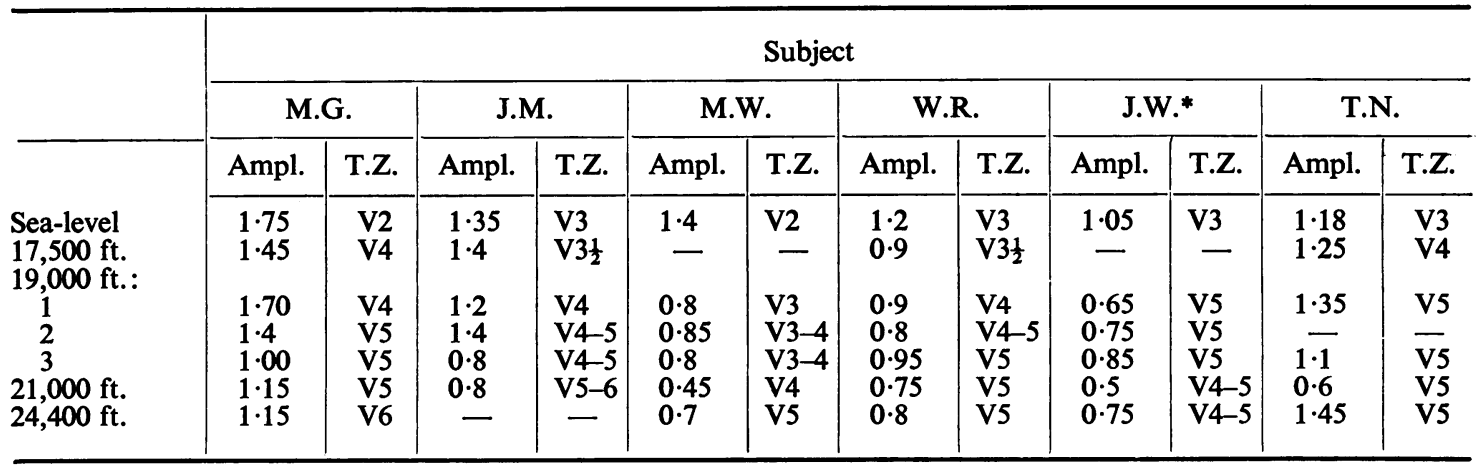

The three results at $19,000 \mathrm{ft}$. are: (1) the first cardiogram taken at this height, (2) the mean of all other cardiograms taken except for (3) the last cardiogram taken at this height.

* This subject developed an S1,S2,S3 pattern. Only the initial 0.04 sec. of the QRS vector is recorded here. 


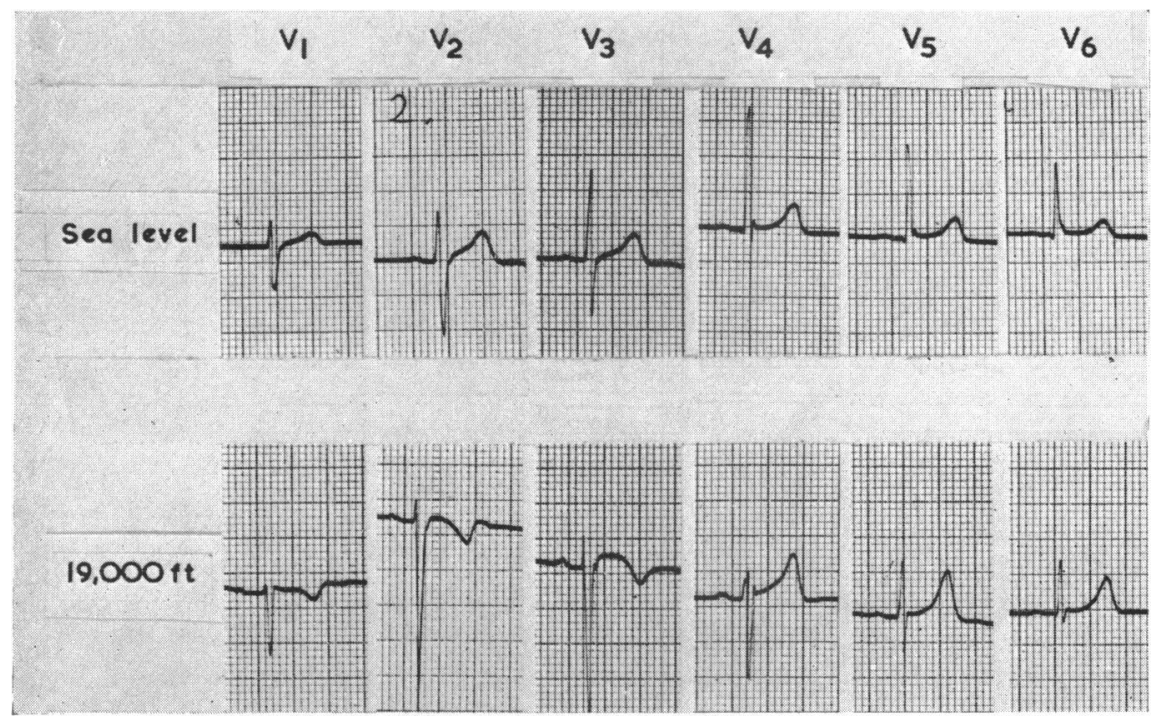

Fig. 4.-V leads at altitude. Subject M.G. showing inversion of the T wave with S-T elevation (V3) and shift of the transition zone to the right. (See also Fig. 5.)

Of the 6 subjects most closely studied, $\mathrm{T}$ wave inversion extended as far as V5 in one, V4 in one, V2 in three, and V1 in one subject. The maximum change was found after some weeks or months at $19,000 \mathrm{ft}$. and did not increase with greater altitude in the spring. In 3 of the 5 traces taken at Camp V at $24,400 \mathrm{ft}$. there was a reversion to an upright $\mathrm{T}$ in chest leads previously having inverted T waves. However, M.W., who was thought to have had pulmonary œdema at Camp V and was flown out from the foot of the mountain, had a cardiogram taken the day after returning to Kathmandu which showed $\mathrm{T}$ wave inversion to V4, whereas this subject had previously had $\mathrm{T}$ wave inversion only as far as V2. One other subject showed persistent $\mathrm{T}$ wave inversion in cardiograms taken three and a half months after return to sea-level: the other three subjects showed normal $\mathrm{T}$ waves by then.

The frontal projection of the $\mathrm{T}$ vector followed that of QRS, but the angular change was less. This resulted in the QRS-T angle increasing, but not significantly. In 3 subjects it remained less than $45^{\circ}$ throughout, while the other 2 subjects, whose sea-level value was $48^{\circ}$, showed no change. Slight $\mathbf{S}-\mathbf{T}$ segment elevation usually accompanied $\mathbf{T}$ wave inversion.

There were no symptoms referable to the heart in any subject, nor was there any correlation between these changes and the climbers' performance.

Oxygen. The only constant effect of oxygen administration was on the amplitude of the QRS complex (Fig. 5). There was no change in the position of the transitional zone, so the increase in the frontal plane projection of the mean QRS vector must be due to a real increase in its amplitude and not due to a change in its direction. Table III shows the results of the eight observations when oxygen was administered. The average increase in amplitude during oxygen breathing is 34 per cent. The ÂQRS did not change on breathing oxygen except on the very first occasion in subject M.G: this subject had a sea-level projection of $+83^{\circ}$. The observation was made after he had spent some three months in the field, mostly over $13,000 \mathrm{ft}$., but only two days at $19,000 \mathrm{ft}$. on that visit. The projection had shifted to $+97^{\circ}$ and on breathing oxygen for 30 minutes it returned to $+82^{\circ}$. No other subject showed any change nor did this subject in a second experiment four months later. Oxygen breathing had no effect on T wave inversion or S-T segment elevation in the præcordial leads. 


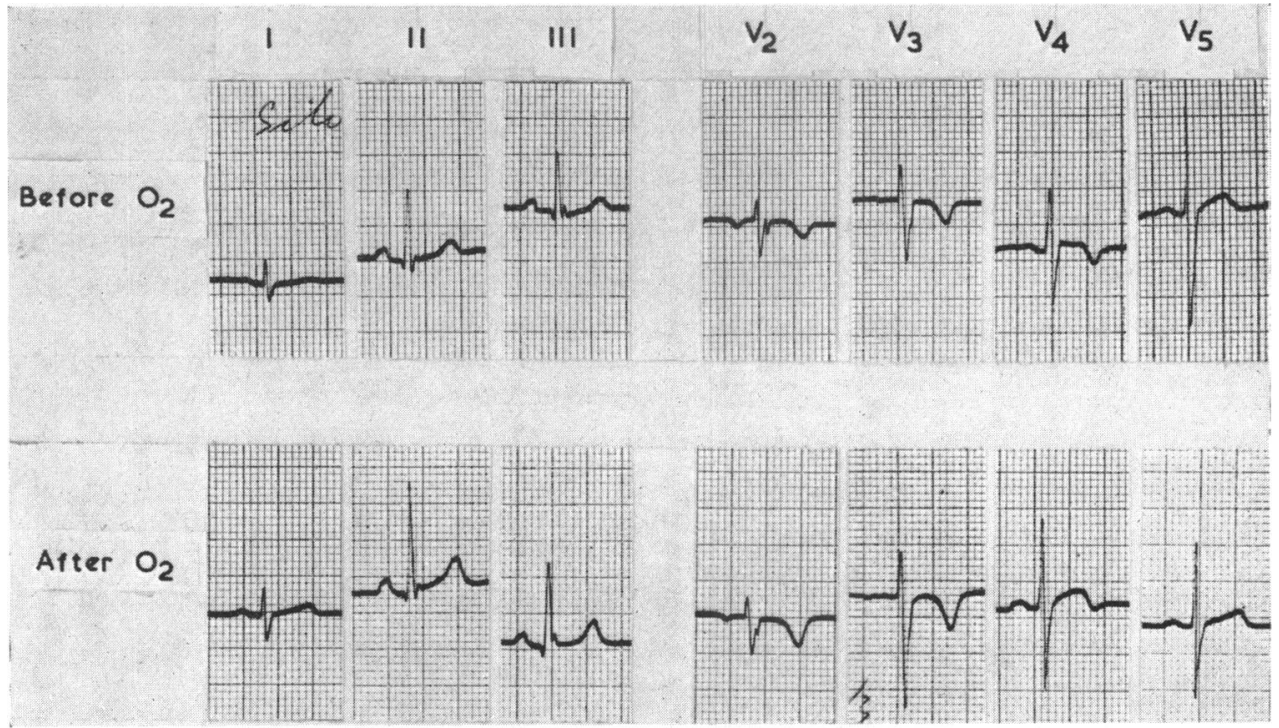

FIG. 5.-The effect of oxygen on the cardiogram at $19,000 \mathrm{ft}$. No change in axis deviation, $T$ wave inversion, S-T segment elevation, or position of transition zone. But amplitude of QRS vector increased 34 per cent.

Exercise. The effect of exercise on the above changes was recorded on two cardiograms at rest and immediately on stopping work. There was no further change in the direction of the mean QRS vector, nor in the mean $\mathrm{T}$ vector, though the amplitude of both was increased. Exercise did, however, produce single focus ventricular extrasystoles in one subject on one occasion (Fig. 6). No other subject showed any arrhythmias. The cardiogram was also used as a heart rate counter during work experiments and though these records are not suitable for examination of the details of the cardiogram pattern, extrasystoles of the type seen in this subject would have been obvious. It is perhaps noteworthy that he was the youngest subject.

TABLE III

Effect of Oxygen Breathing* on Amplitude and Angle of Frontal Projection of Mean QRS Vector (ÂQRS) AND Transitional ZONE (T.Z.) ACross Chest

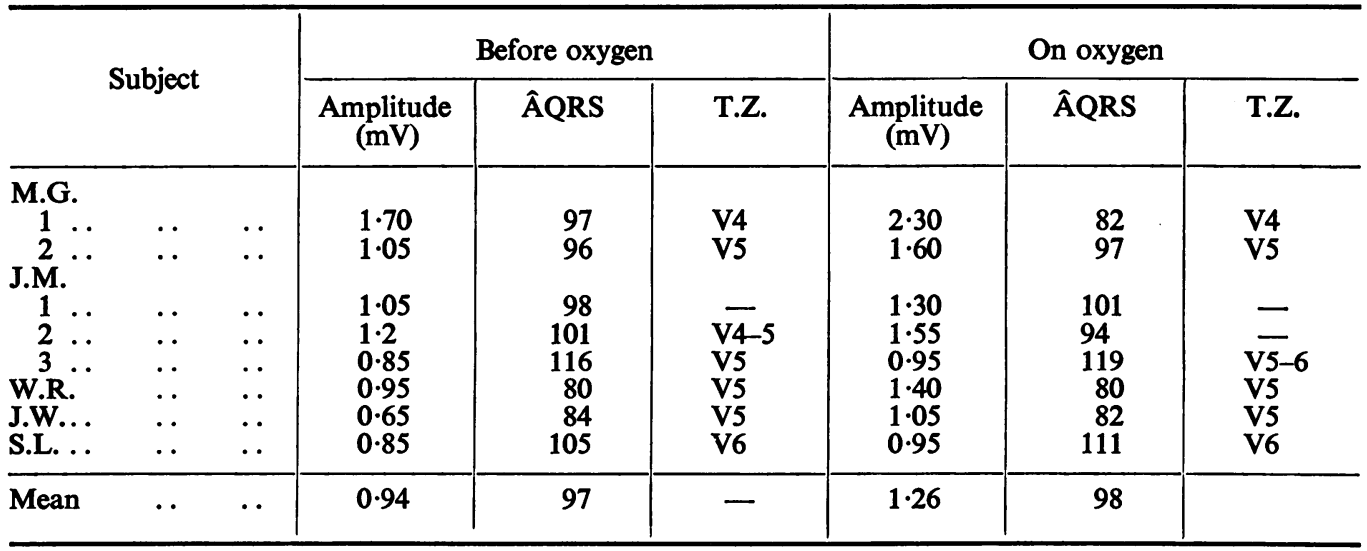

* 100 per cent $\mathrm{O}_{2}$ for $30 \mathrm{~min}$., except experiment 3 on J.M., when 0.51 ./min. was breathed for 9 hours. Mean values do not include the first experiment on M.G., where the change in ÂQRS was reversed by oxygen. 


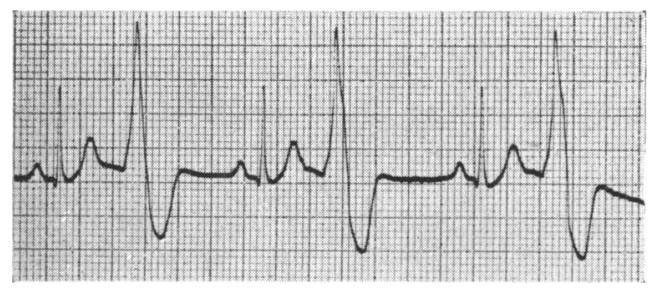

Fig. 6.-Subject M.G. Extrasystoles after exercise (lead II at 19,000 ft.).

Altitude Intolerance. One subject, not included in the six principal subjects, was unable to spend more than a few days at a time at $19,000 \mathrm{ft}$. On returning to base camp at $15,000 \mathrm{ft}$. he immediately recovered on each occasion. Cardiograms taken on this subject at $19,000 \mathrm{ft}$. showed changes similar to those of the other subjects, except that he developed the highest S-T segment elevation found, i.e. $3 \mathrm{~mm}$. in V4.

Sherpas. One cardiogram only was taken at $19,000 \mathrm{ft}$. on each of four high altitude Sherpas, as we had not been able to obtain sea-level records on them, and we were primarily interested in studying the changes in non-residents. One Sherpa also showed an S1, S2, S3 pattern. The ÂRS for the other three are shown in Fig. 1. In this respect and as regards other characteristics of their records they showed no difference from the climbers.

$P$ Wave and $P-R$ and $Q-T$ Intervals. There was no change in shape of the $P$ wave. The $P$ vector followed the changes in the $Q R S$ and $T$ wave vectors. There was no change in the $P-R$ and Q-T intervals.

\section{DisCUSSION}

Right Axis Deviation. The change in the ÂQRS is in accordance with previous work on cardiograms in residents at high altitude (Rotta, 1947) and in newcomers (Peñaloza and Echevarría, 1957; Jackson and Davis, 1960).

Two possible explanations for this shift have been advanced.

1. Positional, where it is argued that the hyperventilation of men at altitude causes a lowering of the diaphragm and a rightward shift of the anatomical axis of the heart.

2. Right ventricular hypertrophy, the mechanism of which is as follows.

$$
\text { Hypoxia } \longrightarrow \underset{\begin{array}{c}
\text { Pulmonary } \\
\text { hypertension }
\end{array} \longrightarrow \begin{array}{c}
\text { Increase in } \\
\text { work of right } \\
\text { ventricle }
\end{array}}{\text { Rentight ventricular }}
$$

High hæmatocrit $\longrightarrow$ Raised blood viscosity- $\longrightarrow$

Both Peñaloza and Echevarría (1957) and Jackson and Davis (1960) discuss the possible importance of both these mechanisms. The additional evidence presented in this study seems to favour the latter explanation as being the more important.

i. In cardiograms taken immediately after exercise when ventilation was considerably raised there was no further change in the ÂQRS.

ii. In the first oxygen breathing experiment there was a reversal of the right axis deviation to the sea-level position. The fact that subsequent experiments produced no change is presumably because there must be a critical time of chronic hypoxia, after which changes in the right ventricle or pulmonary circulation are not reversed by relatively short periods of oxygen breathing. This is in accord with the work of Rotta et al. (1956) who found in catheter studies of natives at altitude that the raised pulmonary pressure was not reduced by oxygen administration, whereas in acute hypoxia studied by Motley et al. (1947) the raised pulmonary pressure produced by breathing a low oxygen mixture returned rapidly to normal on switching to ambient air.

Projection of QRS Vector in Sagittal Plane. Peñaloza and Echevarría (1957) noticed a shift in the transitional zone across the chest to the left during acclimatization to altitude, though the change was less consistent in his subjects. The most likely explanation is clockwise rotation of the heart 
bringing the apex more posterior. Why this should take place is not clear, since the more common result of right ventricular hypertrophy is for the mean QRS vector to become more anteriorly directed (Grant, 1957).

S1, S2, S3 Pattern. This pattern of the QRS developed in one subject on ascending to altitude and was found in one Sherpa. In clinical practice it is usually associated with right ventricular hypertrophy (Grant, 1957). In this subject the pattern was fully developed within a month of reaching our base camp.

Amplitude. The amplitude of the mean QRS vector did appear to be less at altitude in our subjects, as opposed to the finding by Jackson and Davis (1960), but since there was a backward shift of the vector at the same time this may have been only apparent. However, on giving oxygen there was a consistent increase in amplitude without any measurable change in the direction of the vector in any plane. It seems probable that the power of the myocardium is limited by hypoxia at this altitude. In support of this suggestion is the fact that in a companion study it was found that maximum cardiac output on exertion was limited (Pugh, 1963).

$T$ Wave Inversion and $S-T$ Segment Elevation. $T$ wave inversion and $\mathrm{S}-\mathrm{T}$ segment changes in præcordial leads have been reported in men at high altitude (Peñaloza and Echevarría, 1957; Jackson and Davis, 1960), but not to the extent in the present study. Inversion of the $T$ wave in the chest leads indicates a backward shift of the $T$ vector, so that with the simultaneous backward shift of the QRS vector the QRS-T angle in this plane also remains small. Therefore inversion of the $T$ wave in these circumstances is not a bad prognostic sign as the experience of our climbers proved. The two subjects who showed the most widespread $\mathrm{T}$ wave inversion, to V4 and V5 respectively, were two of our strongest climbers and were in the first assault party on Makalu, reaching a height of about $26,500 \mathrm{ft}$. without oxygen, before being turned back by bad weather, while other subjects with minimal $\mathrm{T}$ wave inversion also climbed to $26,000 \mathrm{ft}$. and $27,400 \mathrm{ft}$. without oxygen. These changes cannot be due to the immediate effect of hypoxia because $(a)$ they were not

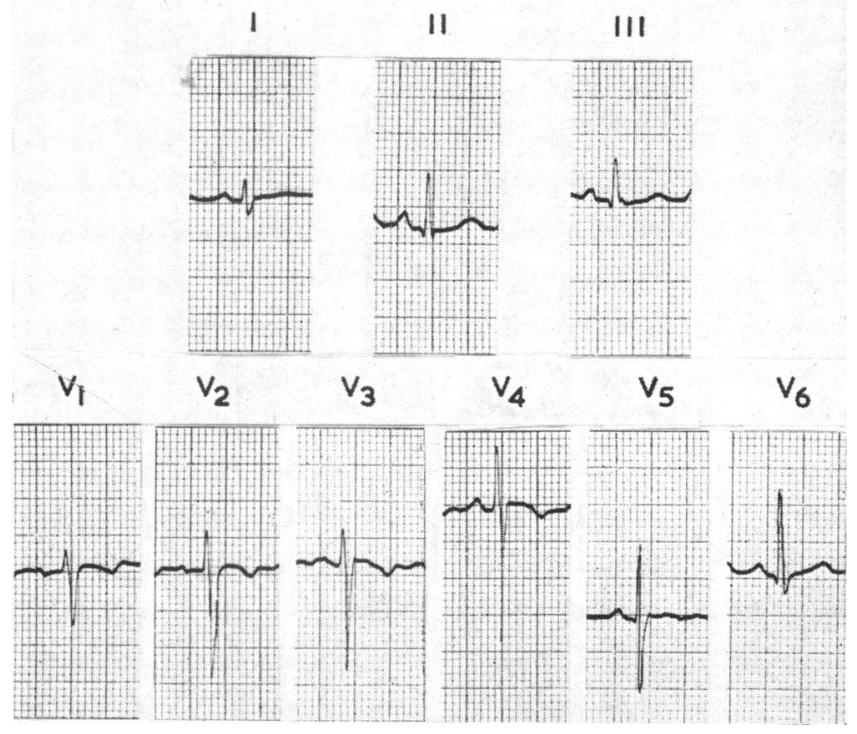

Fig. 7.-Subject W.R. Typical cardiogram of man at $24,400 \mathrm{ft}$. greatest at the highest camp; $(b)$ oxygen breathing did not reverse them; and (c) exercise, which was shown to reduce the arterial oxygen saturation considerably (West et al., 1962), did not increase them.

$T$ wave inversion also seemed to persist longer than the other changes after descent to sea-level, though the evidence is scanty.

In summary, the cardiogram at altitude shows unmistakable signs of right ventricular overload, but perhaps the most surprising finding was that the cardiograms of men as high as $24,400 \mathrm{ft}$. showed such little evidence of the severe physiological stress under which they were working (Fig. 7).

\section{SUMMARY}

The electrocardiograms of climbers were recorded at $19,000 \mathrm{ft}$. at intervals during the winter of $1960-61$ and subsequently at altitudes up to $24,400 \mathrm{ft}$. The effect of oxygen breathing and exercise on the record was also studied. 
There was a shift of direction of the QRS and $\mathrm{T}$ vectors to the right in the frontal plane. In the præcordial leads, there was a shift to the left of the transitional zone of the QRS complex and inversion of the T wave spreading across from right to left (from V1-2 to V4-5), i.e. a backward shift of the QRS and T vector in the sagittal plane. Oxygen breathing did not reverse these changes except in the first oxygen experiment. There was a decrease in the amplitude of the QRS voltage which was reversed by oxygen breathing. The significance of these changes is discussed.

The Expedition was sponsored by "World Book Encyclopædia" of Chicago, U.S.A. The author was in receipt of a personal grant from the Medical Research Council after the Expedition.

I wish to acknowledge my indebtedness to all Expedition members who were my subjects, and especially to Dr. John West who took the cardiograms at Camp V.

\section{REFERENCES}

Grant, R. P. (1957). Clinical Electrocardiography, pp. 79 and 128. McGraw-Hill, New York. Jackson, F., and Davis, H. (1960). Brit. Heart J., 22, 671.

Motley, H. L., Cournand, A., Werko, L., Himmelstein, A., and Dresdale, D. (1947). Amer. J. Physiol., $150,315$. Peñaloza, D., and Echevarría, M. (1957). Amer. Heart J., 54, 811.

Rotta, A. (1947). Amer. Heart $J$., 33, 669.

—, Cánepa, A., Hurtado, A., Velásquez, T., and Chávez, R. (1956). J. appl. Physiol., 9, 328.

Pugh, L. G. C. E. (1963). In preparation.

West, J. B. Lahiri, S., Gill, M.B., Milledge, J. S., Pugh, L. G., and Ward, M. P. (1962). J. appl. Physiol., $17,617$. 